\title{
A JUSTAPOSIÇÃO DO PÓS-HUMANO E DO TRANSUMANO NO GÊNERO DISTOPIA: UMA ANÁLISE DAS TRILOGIAS DIVERGENTE E $A 5^{a}$ ONDA
}

\author{
Eduardo Marks de Marques* \\ Universidade Federal de Pelotas \\ Rio Grande do Sul, BR. \\ Ânderson Martins Pareira ${ }^{* *}$ \\ Universidade Federal de Pelotas \\ Rio Grande do Sul, BR.
}

\begin{abstract}
Resumo:
O presente artigo busca discutir como as correntes transumanistas e pós-humanistas ressignificam o componente humano em distopias contemporâneas. Neste sentido, buscar-se-á cotejar as trilogias Divergente e $A 5^{a}$ onda, duas narrativas sintomáticas do momento político e social atual do ocidente, porém distintas quanto às suas imputações filosóficas acerca dos ideais epistemológicos da transumanidade e da pós-humanidade. Para tal, este artigo utiliza-se das contribuições de Hayles (1999), Wolfe (2009), More e Vitta-More (2013) e Marks de Marques (2014). Este artigo justifica-se por contribuir com os estudos acerca do gênero distopia, os quais têm se destacado nas últimas décadas e têm tornado disponíveis novas ferramentas para melhor entender o gênero e as sociedades das quais ele se origina.
\end{abstract}

Palavras-chave: Distopias contemporâneas; Pós-humanismo; Transumanismo.

\section{THE JUXTAPOSITION OF THE POSTHUMAN AND TRANSHUMAN IN THE DYSTOPIAN GENRE: AN ANALYSIS OF THE TRILOGIES DIVERGENT AND THE $5^{\text {TH }}$ WAVE}

\begin{abstract}
:
This paper aims to discuss the way the philosophical currents of transhumanism and posthumanism re-signify the human component in contemporary dystopias. In this sense, we aim to compare the trilogies Divergent and The Fifth Wave, two narratives that are symptoms of the current Western political and social moment, but distinct in their philosophical imputations about the epistemological ideals of transhumanism and posthumanism. As such, this article is based on the works of Hayles (1999), Wolfe (2009), More e Vitta-More (2013) and Marks de Marques (2014). This work is justified to contribute with the studies about dystopia, which have stood out in recent decades and have made available new tools for dealing with the genre and the society in which it is originated.
\end{abstract}

Keywords: Contemporary dystopia; Posthumanism; Transhumanism.

O desenvolvimento do capitalismo tardio vem transformado o corpo cada vez mais em commodity, ou seja, em um objeto cujo valor se dá através de sua relação com as matrizes e forças econômicas do mercado. $\mathrm{O}$ corpo humano, imperfeito em sua estrutura biológica, torna-se alvo do sistema, que impõe a ele necessidades de melhorias - estéticas e funcionais - para que este corpo possa ser visto como um objeto de desejo por outros corpos. A criação de tais elementos de melhoria do biológico tem sido um dos objetivos da ciência e,

\footnotetext{
*Professor Adjunto de Literaturas de Língua Inglesa e Literatura Comparada no Centro de Letras e Comunicação da Universidade Federal de Pelotas (UFPel). Seu endereço de e-mail é eduardo.marks@mandic.com.br

** Graduado em Licenciatura em letras pela Universidade Federal do Pampa (2012) com especialização na área de Linguagem e Docência (2014), pela mesma instituição. Mestrando do programa de literatura comparada da Universidade Federal de Pelotas (UFPel), atuando principalmente nos seguintes temas: Utopia, Distopia, transumanidade, pós-modernidade e pós-humanidade. Seu endereço de e-mail é andersonmartinsp@gmail.com.
} 
assim, a relação entre o humano e o tecnológico transforma e ressignifica o conceito de humanidade. Dessa forma, movimentos filosóficos como o pós-humanismo e o transumanismo passam a fazer parte das discussões que norteiam as inquietações para com o humano relacionadas ao presente e ao futuro. No entanto, a incerteza do futuro, relacionada aos medos e angústias políticas e sociais do presente, faz com que a imaginação humana consiga construir espaços narrativos possíveis em que a relação entre humanos e a tecnologia, bem como humanos entre si, seja pautada por uma aura de pesadelo político e social, os quais podemos chamar de distopias.

Afastando-se ligeiramente de seus equivalentes do século $\mathrm{XX}$, as narrativas distópicas deixam de possuir como elemento central somente a discussão do político e do social e começam a se articular, também, como questionadoras das implicações na adoção ou na possibilidade de um posicionamento filosófico-social que transcenda às fronteiras do humano. Assim, questionase qual a motivação para a discussão feita pelas distopias contemporâneas de concepções de futuro que partam de premissas pós-humanas ou transumanas, visto que estas são por vezes antagônicas. Para tal discussão, buscar-se-á cotejar duas trilogias relativas ao momento atual do gênero, porém distintas quanto às suas imputações filosóficas. Neste cenário, a trilogia Divergente é representativa de uma realidade enfaticamente transumana e $A 5^{a}$ Onda é concebida a partir de um ambiente agudamente pós-humano.

Neste âmbito é importante primeiramente analisar o sentimento utopista que dá vazão às expectativas, sejam elas de sonho ou pesadelo. O utopismo, segundo Lyman Tower Sargent (2010), tem sido parte premente da sociedade. Sonhar com uma realidade idealizada é um processo natural para Sargent e tal recurso cria "não-lugares". Todavia, as mudanças sofridas na sociedade atingem também esse lugar efêmero. Dessa forma, analisando este "não-lugar", Chris Ferns (1999) vincula a distopia à utopia, ainda que ambas possuam construção estéticas distintas. Para o autor, o ideal pessimista, marca da distopia, aparece após as decepções com promessas sociais não concretizadas. É necessário, portanto, entender o enquadramento histórico de ambos os gêneros. As primeiras utopias tiveram em seu contexto de criação um mundo no qual os avanços tecnológicos eram crescentes. Com o desenvolvimento da navegação, a ideia de encontrar sociedades diferentes permeava o imaginário do século XVI, e a possibilidade de encontrar uma sociedade mais evoluída inspirou A Utopia (1516) de Thomas More. Desde então, as promessas tecnológicas foram colaborando para uma visão mais positivista de história humana.

Este contexto possibilitou a abertura da sociedade para as utopias, as quais problematizavam a sociedade do público leitor por meio de realidades idealizadas. A exemplo disto, a obra Nova Atlântida de Francis Bacon, publicada originalmente em 1627, se utilizou largamente da tecnologia para criação e manutenção da sua sociedade utópica. Os usos da tecnologia implementam as colheitas, melhoram a saúde e o bem-estar, mas ferem alguns conceitos que atualmente são considerados parte da ética humana. Tanto a utopia como a distopia são termos estritamente arraigados à sociedade; o que enquadra tais obras a essas definições é o conceito de caos ou perfeição estabelecidos pela sociedade que os descrimina. Pode-se dizer, por exemplo, que leitores contemporâneos talvez tivessem dificuldade em considerar alguns textos antigos como utópicos.

Várias crises sociais causaram o descrédito da utopia e posterior ascensão da distopia. Porém, após o mundo passar pelo Holocausto e pela Segunda Guerra Mundial, a tecnologia, outrora base de muitos sonhos, torna-se arma de controle e massacre, criando um cenário ainda mais favorável à proliferação do gênero. M. Keith Booker (1994) pontua não apenas os eventos sociais como facilitadores da proliferação de tais textos, mas também as descobertas científicas como a publicação do livro A origem das espécies de Charles Darwin (1859), que ressignificou a existência humana, questionando a fé cristã e a gerência do destino da humanidade, a partir de um ser superior. Na obra de Darwin, a evolução não é vista mais como desenvolvimento constante, mas como processo aleatório, elemento que demostrara a fragilidade da espécie humana frente ao universo.

Outro fator elencado por Booker (1994) como mudança de paradigma acerca da concepção positivista de história e de sociedade é a publicação em 1850 da Se- 
gunda Lei da Termodinâmica pelo físico Rudolf Clausius, que desenvolve a ideia de entropia e demonstra que, quanto mais o sistema evolui, mais energia é consumida até que, por fim, entra em colapso. Dessa forma, a história humana estaria fadada ao caos e ao eventual aniquilamento. Neste cenário, a utopia perde espaço e narrativas pessimistas de futuro têm fácil aceitação do público da época. Entretanto, a distopia nem sempre se ocupou em discutir a essência humana em si; principiou discutindo a problemática do humano inserido ao social. Vários textos têm buscado estabelecer padrões e lidar com as manifestações propostas pelo gênero desde seu surgimento. Tal marco, segundo Gregory Claeys (2010, p.110), estaria localizado em meados de 1756 com a publicação da obra Vindication of Natural Society de Edmund Burke.

Claeys (2010) divide o gênero distopia em dois momentos distintos, em um ensaio nominado "The Origins of Dystopia: Wells, Huxley and Orwell". O autor redimensiona a famosa tríade do lugar de textos fundadores para a categoria de segundo momento do gênero, um período no qual a ênfase do não-lugar distópico era o cenário político e social. Contudo, as distopias deixaram de abordar essa temática como elemento central, e, ao invés disso, começaram a focalizar o componente humano e a refletir, em seus universos atrozes, um futuro em que a humanidade não perdeu os seus direitos sociais ou "humanos" básicos, mas deixou de adequar-se ao próprio conceito de humano.

Compreendendo este novo momento do gênero, Eduardo Marks de Marques (2014) se apropria das divisões sinalizadas por Claeys e cunha um terceiro momento no gênero distopia, o qual denomina terceira virada distópica. Para o autor, o elemento central das distopias não está focado no social ou no político, mas sim no corpo transfigurado pelo capitalismo tecnológico e, a saber:

... [os] romances distópicos, principalmente, publicados a partir da década de 1990 rejeitam a mera leitura política proposta pelas distopias clássicas e propõem a discussão dos ideais filosóficos e sociais do transumanismo e póshumanismo a partir da centralidade do corpo transumano como resultante do modelo dis- tópico. Os romances que compõem o que chamo de terceira virada distópica são aqueles em que o centro do ideal utópico não está em uma forma centralizada de controle social, político e/ou cultural sobre os indivíduos, mas, sim, na relação entre o corpo orgânico (falho, defeituoso e imperfeito) e as promessas tecnológicas advindas do modelo capitalista pós-moderno em melhorá-lo e aperfeiçoá-lo e que, ao fazêlo, negam a essência orgânica do ser humano. (MARKS DE MARQUES, 2014, p.20)

Como visto na passagem acima, Marks de Marques sinaliza a tecnologia atrelada ao capitalismo e as correntes filosóficas pós-humanistas e transumanistas, decorrentes deste processo, como indutoras de um pensamento distópico de terceira virada. O sistema econômico é muito abordado em distopias de segunda virada, como no caso de We, de Zamyatin, e de outras distopias do mesmo momento. Porém, como se pode observar, a problemática do capitalismo na terceira virada não se faz sentir apenas socialmente, mas invade e transfigura o corpo dos indivíduos. A ética com relação à instituição corpórea não se restringe à vida ou à morte do corpo, mas transpassa a sua forma e modifica até mesmo sua essência ou a relação entre esses seres com outros diferentes de si.

Existe, contudo, uma oposição filosófica entre estas correntes de pensamento no que tange à posição do componente humano. Para melhor observarmos tal disparidade é profícuo pontuar as bases do humanismo, já que é este o conceito inicial e sobre o qual ambos movimentos irão se sobrepor. A visão humanista ainda que ligada à igreja traz consigo a razão e destitui Deus e a religião do pedestal de "verdade inquestionável" para colocar em seu lugar a figura da própria humanidade e de sua razão, a qual, por sua vez, julga e subjuga a natureza na qual está inscrita:

[o] verdadeiro humanista (não o humanista 'gramático ou pedante) penetra a alma e o espírito do clássico para recobrar os valores humanos, para exaltar-se em contato com as antigas virtudes e com os heróis reavivados pelo sopro da arte imortal. O humanista extrai da humanidade clássica valores válidos para a humanidade assim como os antigos Padres 
122 Eduardo Marks de Marques e Ânderson Martins Pareira, A justaposição do pós-humano e do transumano...

da Igreja. Estes valores não contrastam com a concepção cristã de homem; sendo o Cristianismo o primeiro a percebê-los e aprofundá-los incomensuravelmente. (SCIACCA, 1960, p 12; nossa tradução) 1

Como visto na passagem acima, o humanismo acredita que a razão e o enfoque no ser humano podem não apenas melhorar a espécie, mas também a igreja e a própria fé. Tudo estaria a serviço da razão, sendo o humanismo o primeiro passo para o iluminismo que se seguiria, no qual o ser humano, como sugerido por Hegel (1912 apud SCIACCA, 1960, p 21), dá início à ressignificação do cristianismo como evento histórico e não como verdade superior à história.

Ao referenciarem-se a este humanismo, o pensamento pós-humanista e o transumanista, dentro do recorte teórico utilizado neste trabalho, são movimentos opostos entre si. Segundo N. Katherine Hayles (1999, p. 22), o pós-humanismo posiciona-se contra o movimento humanista, admitindo que a humanidade não é o âmago do universo, mas que várias formas inteligentes podem existir. Sendo assim, o "centro" que teria o discernimento e a racionalidade como prerrogativas e seria sinônimo de humanidade, passa a não existir, pois outros seres poderiam subsistir e compartilhar de uma racionalidade similar:

Destes preconceitos, nenhum é mais sintomático do estado atual da bioética do que o preconceito baseado na diferença de espécies e do que a incapacidade de abordar as questões éticas levantadas por mudanças dramáticas nos últimos trinta anos em nosso conhecimento sobre a vida, a comunicação, as emoções e consciência de uma série de espécies não-humanas - um preconceito que a bioética compartilha com o cerne de um humanismo secular que a bioética contemporânea e seus cenários de ficção científica parecem (mas só parecem) ter sempre deixado para trás (WOLFE, 2009, p.56; tradução nossa) 2

No mesmo sentido, Cary Wolfe (2009) acredita que o movimento pós-humanista emancipa ao mesmo patamar seres como animais, robôs ou alienígenas. A consciência não é mais humana, mas pós-humana. Wolfe, ao refazer o percurso histórico do ser humano frente aos demais seres, constata os efeitos colaterais do humanismo sentidos ainda hoje, cujos malefícios deveriam ser combatidos. Pode-se inferir, portanto, que esta corrente se trata de uma descentralização e, segundo o autor, não necessita recuperar para isso traços humanistas ou se constituir como anti-humana.

Já o transumanismo não se opõe ou descentraliza o humanismo; ao contrário, o intensifica, pois, se no humanismo o ser humano retira a divindade do centro do universo e da representação de beleza, no transumanismo ele destitui do divino a incumbência da evolução de sua espécie. A humanidade seria então capaz de evoluir a si mesma através da tecnologia, e tal evolução estaria a cargo de seu desejo e não de uma ordem divina ou de processos naturais aleatórios.

A ideia é que alguns de nossos conceitos psicológicos, tais como a fé, desejo, ou intenção são tão pouco definidos que eles serão entendidos futuramente pela carência de qualquer base neuronal coerente - exatamente como o conceito de "calórico" fora rechaçado completamente no passado em favor da concepção termodinâmica de calor. O materialismo é revisionista (ou poderia ser chamado, igualmente bem, de funcionalismo revisionista) toma a posição imediata de que os estados mentais seriam reduzíveis a fenômenos físicos, porém somente depois de algumas mudanças significativas e refinamentos serem feitos no conceito psicológico popular. Visto o interesse transumanista em usar o conhecimento cientifico para reconceituar e revisar a arquitetura cognitiva humana, transhumanistas talvez sejam unicamente abertos para esta posição na filosofia da mente. (MORE; VITTAMORE, 2013, p 7)

Como visto na passagem acima, os filósofos transumanistas se utilizam do conceito de calórico para demonstrar o quanto a organização humana atual não estaria apta para imaginar um ideal de produto desta evolução ou possuir uma ampla ideia do que é a transumanidade. Ainda na questão de produto, é importante pontuar que a evolução transumana se entende como um processo de aprimoramento constante e infindável, processo esse denominado extropia. Esses aperfeiçoamentos estariam enfatizados em três grandes áreas: bem-estar, longevidade e inteligência. 
Ainda que existam diferenças basilares nas propostas transumanistas e pós-humanistas, ambas correntes poderiam convergir em um futuro. Esta probabilidade não é comum ao pensamento contemporâneo, pois, para o ser humano corrente, parece que sempre se conviveu com a mesma espécie e que a evolução se deu de forma rápida e definitiva. Não é, pois, comum a estes lidar com outras espécies que possuam um nível similar de racionalidade, mas a transumanidade aponta para uma evolução bastante norteada pelo capitalismo, na qual muito provavelmente diferentes versões de seres poderiam existir e, então, se estabeleceria uma sociedade pós-humana.

A partir desta relação, questiona-se como estes dois modelos filosóficos ressignificam o componente humano em distopias de terceira virada e, como dito, para este estudo serão utilizadas as trilogias Divergente e $A 5^{a}$ Onda, as quais denunciam respectivamente a realidade transumana e pós-humana. A primeira trilogia, escrita por Veronica Roth, se passa inicialmente em uma Chicago futurista que é na verdade um experimento para fazer com que os seres humanos gerem descendentes de uma forma mais controlada e recuperem-se de alterações genéticas em um tempo anterior à narrativa. Esse controle se dá por meio das facções que asseguram uma certa estabilidade social e permitem que os indivíduos troquem carga genética com outros grupos de genes de maneira gradual. A trilogia $A 5^{a}$ Onda, escrita por Rick Yancey, se passa durante uma invasão alienígena e lida com a discussão do humano frente a um rival de certa forma igual a si. Neste confronto, é necessário repensar o que é ser humano para poder entender o inimigo como o "outro" e, portanto, diferente.

É possível inferir que ambas as obras aqui analisadas correspondem a um momento social de ressurgimento da distopia, visto que ambas se tornaram rapidamente sucesso de vendas. Essa concepção é vista também por Noreena Hertz (2015), que desenvolve pesquisa entre adolescentes americanos e cunha o conceito "Geração K" - o qual provém da protagonista Katniss Everdeen de Jogos Vorazes (2008), de Suzanne Collins. O batismo da geração pelo nome da protagonista de uma obra consumida mundialmente sinaliza elementos que destoam das gerações anteriores, pois para a autora os adolescentes que nasceram entre os anos de 1995 a 2002 são mais suscetíveis a questões políticas e sociais, visto que cresceram com a ameaça constante de atentados terroristas e sabendo do papel da tecnologia em tais práticas. Contudo, tal fenômeno se inscreve não apenas nos jovens analisados, mas no mundo como um todo, pois, as obras são altamente traduzidas e consumidas por outros países. A questão de representatividade fenomenológica é interessante para pontuar que as obras aqui analisadas, ainda que não pertencentes a autores com um histórico substancial do gênero, inscrevem-se em uma linhagem de textos que representam a sociedade e os pensamentos transumanistas e pós-humanistas atrelados a ela.

Os conceitos filosóficos aqui abordados são temporalmente sincrônicos. Logo, a questão social e a visão contemporânea para tais correntes são extremamente relevantes no universo das obras. Neste contexto, ambas as trilogias aqui analisadas questionam não apenas a fragilidade do ponto de vista atual, frente a estas possibilidades de futuro, mas também a concepção de tais termos por uma sociedade que ainda não desenvolveu inteiramente meios de conceber tais estruturas:

O lado de fora da cerca: o lugar que ele tanto tentou evitar, que o fez se voltar contra a própria irmã. De qualquer maneira, parece-me um castigo pior do que a morte. A morte é tão rápida, tão certa. No lugar para onde estamos indo, nada é certo. (ROTH, 2014, p. 92)

No excerto pertencente à trilogia Divergente, podese observar a questão do humano frente a este futuro transumano ao qual ele desconhece. No contexto da passagem citada, a protagonista Tris não sabe que pertence a um experimento e entende a si mesma e aos outros seres com os quais teve convívio como humanos. Todavia, após uma saga que a guia ascendentemente a um aclaramento quanto a si mesma, ela sabe que acabará por descobrir coisas que a ressignificarão enquanto ser e que mudarão até mesmo seu conceito de humanidade. Colocar a experiência da descoberta como pior que a morte em seu estado físico é sintomático, pois representa, de certa forma, uma morte do ser enquanto produto de um acreditar. 
124 Eduardo Marks de Marques e Ânderson Martins Pareira, A justaposição do pós-humano e do transumano...

A ineficiência da geração presente em lidar com estes movimentos pode ser também observada na obra de Yancey. A personagem, em vários momentos da obra, descreve sua vida pregressa e narra a incapacidade de uma ideia global do que estaria em jogo em uma sociedade que se torna pós-humana:

É impossível ter certeza, mas aposto que os Outros sabiam dos alienígenas que imaginávamos. E aposto que eles acharam tudo muito engraçado. Eles devem ter rolado os traseiros no chão de tanto rir. Se é que têm senso de humor... ou traseiros. Eles devem ter rido como nós rimos quando um cão faz algo especialmente bonitinho e idiota, «Ah, esses humanos, tão bonitinhos e idiotas! Eles acham que gostamos do que fazem! Não é lindo?" (YANCEY, 2013, p.13)

Na passagem acima, pode-se observar ainda um momento de transição, no qual existe uma busca de pertencimento a um ideal de humanidade, o qual é caracterizado pelo uso do "nós" enquanto oposição aos “outros". Há, também, uma luta para retornar à antiga sociedade, visto que a nova sociedade atroz é exatamente a pós-humana. É importante pontuar que em ambas as trilogias aqui analisadas esses movimentos são ponto central na criação do universo distópico; logo, a ideia central das distopias de terceira virada é demonstrar a derrocada social decorrente do acontecimento ou da adoção de tais sistemas.

Outra aproximação entre as duas obras está no ideal utópico das mesmas Dunja M. Mohr (2007), em seu texto intitulado "Transgressive Utopian Dystopias: The Postmodern Reappearance of Utopia in the Disguise of Dystopia", afirma a existência de um subtexto utópico dentro das distopias modernas e até mesmo uma mescla entre ambos os gêneros, dos quais os textos resultantes poderiam ser vistos ora como distopia ora como utopia, dependendo do ponto de vista. Neste sentido, ao se analisar Divergente ou $A 5^{a}$ Onda é inegável um subtexto utópico muito similar em ambas as narrativas. Nelas há uma noção de que o componente humano deveria ser intocado pela tecnologia, e a utopia, para tal realidade, estaria na retomada de elementos que deixariam o indivíduo em sintonia com um ideal humano, imutável e intrínseco à nossa espécie desde seus primórdios. Essa revisitação à essência humana na busca de um ideal utópico danificado pela sociedade e a tecnologia está presente em ambas as trilogias aqui analisadas e é paralela à imputação dos conceitos de pós-humano ou transumano feita pelo gênero na terceira virada distópica.

Tal leitura é facilmente apreensível nas obras. No caso de $A 5^{a}$ Onda, a personagem central é batizada de Cassiopeia, mas é comumente chamada de Cassie. A pronúncia de Cassiopeia em inglês se assemelha à junção do nome Cassie e utopia [kæsioð' pi:ə], sendo possível ler tal nome como uma referência a utopia de Cassie. Esta aproximação é significativa, pois a personagem corporifica de forma pungente o subtexto utópico dentro da obra. Ela se questiona sempre sobre o conceito do humano, para distinguir-se dos outros seres aos quais nomeia sintomaticamente como "Outros", fazendo com isso uma clara oposição entre eles e os humanos. Na fala da personagem podese depreender uma necessidade de assimilar para si uma ideia de humanidade e a partir dela estabelecer o inimigo no campo de batalha: "Porque, se eu for a última, então eu sou a Humanidade. E se essa for a última guerra da Humanidade, então eu sou o campo de batalha" (YANCEY, 2013, p.167).

A busca de uma essência humana parece natural em uma sociedade pós-humanista como a de $A 5^{a}$ Onda. Porém, este mesmo questionamento ocorre na sociedade transumana de Divergente. O corpo tornase centro de controle e pode-se observar como os soros - drogas químicas utilizadas para a manutenção de cada facção - corroboram na manutenção do regime e de que forma são transgredidas pela divergência localizada no corpo da personagem Tris:

O que acontecerá se eles suprimirem as atividades do meu córtex pré-frontal? Se eles prejudicarem minha capacidade de tomar decisões? E se o soro funcionar e eu me tornar uma escrava das simulações, como os outros? E se eu me esquecer completamente da verdade? (....) Não tinha ideia de que toda a minha personalidade, todo o meu ser, poderiam ser descartados como um subproduto da minha anatomia. 
E se eu realmente for apenas uma pessoa com um grande córtex pré-frontal...e nada mais? (ROTH, 2013 [2012], p. 330)

$\mathrm{Na}$ citação acima, proveniente do segundo romance da saga, a personagem é submetida a testes que objetivam controlá-la por meio de uma hipnose induzida chamada simulação. Nela, os indivíduos são controlados pelo governo como computadores e a resistência fisiológica da personagem a este domínio é vista como um fato a ser estudado e resolvido para que a automação de pessoas seja desenvolvida inteiramente na distopia. Assim, o controle e a divergência estão intimamente ligados, já que a segunda precisa ser dominada ou descartada para a perseverança do regime.

É importante pontuar que a grande questão é a da evolução e possível diferença evolutiva da personagem que tem seu corpo inscrito em outro patamar evolutivo que a protege de ser manipulada. A discussão que resulta é: até que ponto a essência humana está atrelada a esse corpo físico diferenciado e se de fato está, e, também, se este, sendo distinto dos demais, ainda pode ser chamado humano para aquela comunidade. No terceiro romance da trilogia, Tris descobre que pertencia a um experimento que objetiva o controle dos danos genéticos:

Se as pessoas geneticamente puras causaram guerras e devastações terríveis no passado, na mesma magnitude das quais pessoas geneticamente danificadas supostamente causam agora, então, qual é a base por trás da crença de que precisamos gastar tantos recursos e tanto tempo trabalhando para corrigir os danos genéticos? Qual é a utilidade dos experimentos, afinal, exceto convencer as pessoas certas de que o governo está fazendo alguma coisa para melhorar nossas vidas, mesmo que não esteja? (ROTH, 2014 [2013], p.254)

Como é possível observar, Tris questiona o componente humano para além dos danos genéticos causados. A protagonista demonstra não só um olhar político mais amplo, mas também uma questão social que pode ser mais importante do que os próprios genes na caracterização dos personagens. Essa leitura se embasa também no fato de a personagem não fazer distinção entre si, geneticamente pura, e Tobias, geneticamente danificado. A crítica da passagem acima se dá também na ideia de culpar a genética e buscar uma evolução do corpo, enquanto o entorno é o que realmente dá forma ao ser. Esta visão vai ao encontro do que afirma Bryan J.Turner no livro The Body and Society: Explorations in Social Theory (2008), que inscreve o corpo como materialidade essencialmente cultural e, portanto, produto da sociedade.

Ele não podia ser muito mais velho do que eu. Teria 18. Talvez 19. Mas, droga, em minha opinião ele poderia ter 719 anos. Cinco meses se passaram, e ainda não tenho certeza se a $4^{\text {a }}$ Onda é humana ou alguma espécie de híbrido, ou mesmo os próprios Outros, embora eu não goste de pensar que os Outros tenham exatamente a nossa aparência, falem como nós e sangrem como nós. Gosto de pensar nos Outros como sendo... bem, outros. (YANCEY, 2013, p. 22)

O excerto acima foi retirado de $A 5^{a}$ Onda. Nele, como pode-se observar, o corpo também é levado como uma questão central nas distopias pós-humanas. Todavia não são apontadas diferenças entre corpos e suas possíveis evoluções nesta narrativa, mas, ao contrário, os alienígenas se utilizam de corpos humanos. Fisicamente a única distinção é a existência de uma pequena estrutura alienígena que se localiza no cérebro e faz com que esta consciência não se desenvolva como humana, e sim seja um ser adjetivável como "outro". Uma das questões levantadas por essa situação é a essência humana para além do corpo, já que ambos os seres possuem uma estrutura muito similar, mas se diferenciam em nível de consciência. Contudo, no decorrer da trilogia existe a derrocada deste ideal de distinção, mostrando que há similaridade destas consciências e existe possibilidade de troca entre elas, ainda que a distopia não aponte para a possibilidade de existência de harmonia entre consciências de espécies distintas.

A partir do exposto, pode-se depreender a importância das correntes filosóficas aqui explicitadas e as mudanças na visão do humano decorrentes de tais movimentos. Neste cenário, a distopia de terceira virada desempenha um papel singular, pois debate as pos- 
sibilidades de insucesso, os impasses éticos, políticos e sociais, mas de uma forma diferente da que é proposta pelas distopias clássicas. O ponto das distopias contemporâneas não é a ruína futurística do humano enquanto ser social, mas a ruína do humano enquanto conceito.

O que existe tanto nas distopias transumanas quanto nas pós-humanas é um temor a ambos os sistemas e às ressignificações sociais que corroboram a extirpação dos componentes humanos. Pode-se aventar que seja esse o motivo por trás da discussão e do foco na essência que define a humanidade frente a realidades e modelos sociais que exacerbam esta reflexão. $\mathrm{Na}$ discussão do humano, questões como consciência e corpo emergem naturalmente, pois são intrínsecas ao pensar no indivíduo enquanto ser pensante e enquanto corpo que perfomatiza e dá vazão a essa consciência. A questão da divisão de mente e corpo já problematizada por René Descartes no Discurso do método, publicado originalmente em 1637, parece ainda refletir na forma como se concebe essas estruturas e a essência de cada uma separadamente, ou do conjunto para a interpretação do que é a essência do humano. Entretanto, está discussão não é finda e nem passível de conformidade geral, mas vem sendo atualizada pela filosofia e também pela literatura, como é o caso da distopia contemporânea.

\section{Notas}

1. Do original: [...] el verdadero humanista (no el humanista 'gramático' o pedante) trata de penetrar el alma y el espiritu de la clasicidad para recobrar los valores humanos, para exaltarse en contacto con las antiguas virtudes y con los héroes vivificados por el soplo del arte inmortal. El humanista toma de la humanidad clásica valores válidos para a humanidad encuentra, como los antiguos Padres de la Iglesia, que estos valores no hacen contraste con la concepción cristiana del hombre; de manera que el Cristianismo es el primero en adquirir conciencia de esto y en profundizarlo inconmensurablemente.

2. Do original: Of these prejudices, none is more symptomatic of the current state of bioethics than prejudice based on species difference, and an incapacity to address the ethical issues raised by dramatic changes over the past thirty years in our knowledge about the lives, communication, emotions, and consciousness of a number of nonhuman species-a prejudice that bioethics shares with the very core of a centuries-old humanism that contemporary bioethics and its sci-fi scenarios appear (but only appear) to have always already left behind.

\section{Referências}

BOOKER, M. Keith. Dystopian Literature: A Theory and Research Guide. Westport: Greenwood, 1994.

CLAEYS, Gregory. "The origins of dystopia: Wells, Huxley and Orwell”. In: CLAEYS, Gregory (Ed.). The Cambridge Companion to Utopian Literature. Cambridge: Cambridge University Press, 2010. p. 107131.

DESCARTES, René. Discurso do Método. Tradução de: Marian Ermantina Galvão. São Paulo: Martins Fontes, 1996 [1637].

FERNS, Chris. Narrating Utopia: Ideology, Gender, Form in Utopian Literature. Liverpool: Liverpool University Press, 1999.

HAYLES, N. Katherine. How We Became Posthuman: Virtual Bodies in Cybernetics, Literature, and Informatics. Chicago: The University of Chicago Press, 1999.

HERTZ, Noreena. Generation K: Who are they, and what do we know about them?. New York Times, New York, ed. Women in the world, n.p., 2015.

MARKS DE MARQUES, Eduardo. "Da centralidade política à centralidade do corpo transumano: movimentos da terceira virada distópica na literatura". Anuário de Literatura, cidade, Florianópolis, vol. 19, No. 1, p. 10-29, 2014.

MOHR, Dunja M. “Transgressive Utopian Dystopias: The Postmodern

Reappearance of Utopia in the Disguise of Dystopia". Zeitschrift für Anglistik und Amerikanistik (ZAA), Heidelberg, No. 55.1, p.5-24, 2007.

MORE, Max; VITTA-MORE, Natasha. The Transhumanist Reader. Pondicherry: Wiley-Blackwell, 2013.

RAPP, DAVID. "Goodreads Choice Awards Announced; Divergent Voted Favorite Book of 2011". 06 Dez 2011. Disponível em: <http://reviews.libraryjournal. com/2011/12/in-the-bookroom/goodreads-choiceawards-announced-divergent-named-favorite-bookof-2011/>. Acesso em: 29 Abril 2017.

ROTH, Veronica. Divergente. Rio de Janeiro: Rocco Jovens Leitores, 2012 [2011].

Insurgente. Rio de Janeiro: Rocco Jovens Leitores, 2013 [2012].

Convergente. Rio de Janeiro: Rocco Jovens Leitores, 2014 [2013]. 
SARGENT, Lymar Tower. Utopia: A very short introduction. New York: Oxford, 2010.

SCIACCA, Michele Federico. Qué es el humanismo. Buenos Aires: Editorial Columba, 1960.

TURNER, Bryan. J. The Body and Society: Explorations in Social Theory. 3.ed. Los Angeles: Sage, 2008.

WOLFE, Cary. What is Posthumanism?. Minneapolis: University of Minnesota Press, 2009.

YANCEY, Rick. A $5^{a}$ Onda. Curitiba: Fundamento, 2013. E-Book. ISBN 978-8539506644. Disponível em: $<$ https://www.amazon.com.br/5\%C2\%AA-OndaRick-Yancey/dp/8539506645>. Acesso em: 16 Agosto 2016.

O Mar Infinito. Curitiba: Fundamento, 2015. E-Book. ISBN 978-8539509379. Disponível em: <https://www.amazon.com.br/Mar-Infinito5\%C2\%AA-Onda/dp/8539509377/ref=pd_sim_14_1? $\mathrm{ie}=\mathrm{UTF} 8 \& \mathrm{psc}=1 \& \mathrm{refRID}=$ ZKYQSZZG8WQ6YFRSA $1 \mathrm{ND}>$. Acesso em: 16 Agosto 2016.

A Última Estrela. Curitiba: Fundamento, 2016. E-Book. ISBN 978-8539509386. Disponível em:<https://www.amazon.com.br/\%C3\%9AltimaEstrela-3-S\%C3\%A9rie-Onda/dp/8539509385/ ref $=$ pd_sim_14_2? ie $=$ UTF $8 \& p s c=1 \&$ refRID $=$ ZK YQSZZG8WQ6YFRSA1ND>. Acesso em: 16 Agosto 2016.

Recebido em: 15/11/2016

Aceito em: 25/02/2017 